\section{A Lei de Anistia e o Estado democrático de direito no Brasil}

Glenda MEZAROBBA. Um acerto de contas com o futuro - a anistia e suas conseqüências: um estudo do caso brasileiro. São Paulo, Humanitas/Fapesp, 2006. 271 páginas.

\section{Andrei Koerner e San Romanelli Assumpção}

Um acerto de contas com o futuro trata da mais relevante questão atual para a construção de um Estado democrático de direito no Brasil: as reparações às violações de direitos humanos praticadas por agentes do Estado durante o regime autoritário.

O próprio título do livro já anuncia a gravidade e a atualidade da questão, onipresente na agenda política nacional desde os meses que sucederam o golpe civil-militar de 1964, ao longo do regime autoritário, durante a transição até a construção da nova ordem democrática.

Glenda Mezarobba apresenta este processo numa narrativa minuciosa e precisa, resultado de profunda investigação empírica, realizada em documentos oficiais, entrevistas e artigos de imprensa escrita, e de seu marcado talento narrativo, provavelmente adquirido em sua experiência profissional de jornalista. Ela mobiliza o instrumental teórico e metodológico da ciência política, notadamente a bibliografia sobre democracias contemporâneas, transições à democracia, direitos humanos e justiça de transição. Tem-se, então, um estudo de caso sobre um processo político que se configura como caminhos e encruzilhadas em que se enveredaram as políticas de reparação das violações de direitos humanos no Brasil nas últimas três décadas. Mostra que, nesse processo, lideranças políticas, agentes institucionais, partidos e organizações da sociedade civil negociam medidas políticas de reparações, reconhecimento, responsabilidade objetiva e, mais recentemente, de memória, as quais circulam em torno da questão diante da qual se levantam vetos absolutos, opostos por uma parcela dos militares e pelas lideranças políticas que os apóiam. Pois aquelas medidas jamais chegam a tocar nos temas da verdade para a reconstituição dos eventos e das responsabilidades individuais, da responsabilização, por meio de julgamentos criminais que venham a determinar a punição dos responsáveis, ou da reforma institucional dos aparatos de inteligência e das forças armadas em geral.

No corpo do livro - originalmente uma dissertação de mestrado defendida em 2003 no Departamento de Ciência Política da FFLCH/USP -, a autora caracteriza os três momentos do processo político de acerto de contas a partir dos marcos legislativos que se configuraram até 2003: a Lei de Anistia de 1979; a Lei dos Desaparecidos de 1995; e a Lei 10.559 de 2002. No pós-escrito, redigido em agosto de 2006, ela dá conta de como a questão foi encaminhada pelo governo de Luís Ignácio Lula da Silva, cujas ações parecem configurar um novo momento do processo.

Segundo Glenda, a anistia é uma reivindicação antiga, mobilizada por expoentes do meio político e intelectual pouco após o golpe militar de 1964. Essas reivindicações têm uma trajetória ascendente na sociedade civil organizada brasileira até o período de promulgação da Lei 6.683, a Lei de Anistia, num movimento que envolveu entidades - como a Conferência Nacional dos Bispos do Brasil, as Comunidades Eclesiais de Base, a Comissão de Justiça e Paz, a Ordem dos Advogados do Brasil, a Associação Brasileira de Imprensa, a Sociedade Brasileira pelo Progresso da Ciência, a Anistia Internacional -, organizações criadas especificamente em torno do problema da anistia brasileira - como o Movimento Feminino pela Anistia, os diversos Comitês Brasileiros pela Anistia - e a realização de Encontros Nacionais dos Movimentos de Anistia. Apesar de toda esta movimentação pelos direitos de anistia, a autora considera que esta lei foi estabelecida basicamente nos termos almejados pelo governo, que pretendia estabelecer a pacificação e o esquecimento favorável aos integrantes do aparato repressivo, mais do que promover justiça e esclarecimento da verdade a suas vítimas - numa tentativa de anistia que a autora classifica como "conciliação pragmática". Glenda considera que este limite deveu-se, em parte, ao enorme poder de pressão que os militares ainda possuíam e ao fato de que o regime autoritário não tinha sido extinto.

O envolvimento da sociedade civil brasileira com esta causa arrefeceu após a lei de 1979, embo- 
ra muitas vítimas do arbítrio e familiares de desaparecidos e mortos durante o regime autoritário tenham permanecido empenhados na luta por seus direitos civis, políticos e socioeconômicos, o que levou à promulgação da Lei 9.140 de 1995, a Lei dos Desaparecidos. Este segundo marco legislativo formalizou o reconhecimento da responsabilidade do Estado brasileiro por graves violações de direitos humanos ocorridas durante o regime autoritário e estabeleceu o direito dos familiares de desaparecidos requererem atestado de óbito e indenizações, num avanço significativo rumo ao "resgate moral das vítimas do arbítrio”. Segundo esta legislação, cabia aos familiares mostrar que os desaparecidos foram vítimas de arbítrio e apontar os indícios sobre as circunstâncias das mortes. Naquele momento, não era do interesse do Estado, menos ainda das Forças Armadas, que os crimes contra a humanidade, cometidos durante as perseguições políticas, viessem a ser investigados e revelados.

O "resgate moral das vítimas" seria ampliado em um terceiro momento do processo de reparação às vítimas do arbítrio, que começou a ser delineado em 1996, quando ex-perseguidos políticos reunidos em diversas entidades unificaram seu discurso, conseguindo que, em 2001, o governo enviasse ao Congresso Nacional uma medida provisória tratando da reparação econômica aos que foram impedidos de exercer suas atividades em razão do arbítrio do regime autoritário. Em meio à intensa discussão entre governo, parlamentares, militares e grupos de defesa dos direitos de anistia, a medida provisória foi reeditada em agosto de 2002 e, em novembro do mesmo ano, transformada na Lei 10.559, que dá ao anistiado o direito à reparação econômica de caráter indenizatório; à contagem, para todos os efeitos, do tempo em que esteve afastado de suas atividades profissionais devido ao arbítrio do regime autoritário; à conclusão de curso e ao registro de diploma obtido no exterior; e à reintegração aos cargos dos quais se afastaram devido à perseguição política.

No pós-escrito, a autora estende a narrativa do processo até agosto de 2006. Ao longo desse período (e isso se mantém até novembro de 2008) são frustradas as expectativas dos ativistas de direitos humanos, muitos deles quais membros do PT e in- tegrantes do próprio governo Lula, de que a questão seria enfrentada de frente, adotando-se uma política de verdade e de responsabilização individual pelas violações, assim como o compromisso de efetivar as reformas que permitam ampliar a confiança dos cidadãos sobre o respeito, pelos agentes e instituições estatais, dos princípios do Estado democrático de direito. A autora apresenta o processo de elaboração da Lei 11.111, de 5/2005, sobre a classificação de documentos do Estado, as decisões judiciais, as demandas do governo pela abertura dos documentos e as tentativas dos militares de ocultá-los ou destruí-los. Parece que, a partir desses enfrentamentos, configura-se entre as lideranças políticas e os militares uma nova convergência em torno de uma política da memória. Esse processo resulta na colaboração incipiente das autoridades militares, que passam a fornecer documentos e informações demandadas pelo judiciário, na criação de comissão interministerial para classificar os documentos e organizá-los e o anúncio da criação de um centro de referência para a memória das violações dos direitos humanos no Brasil.

Assim, dentro do espírito dos estudos de justiça de transição, a autora ressalta temas relativos a: conciliação e pacificação política, reconhecimento e responsabilidade estatal pelos crimes cometidos, busca da verdade para a determinação das responsabilidades e punição dos culpados. Ressalta também a importância da elaboração de um acervo de documentos, relatos e histórias de vida que fomente a formação de uma memória coletiva a qual, por sua vez, permite ativar os compromissos esperados com a constituição de um Estado democrático de direito.

A pesquisa realizada revela em primeiro plano a tensão entre, de um lado, a afirmação do esquecimento necessário para a "pacificação dos espíritos" e a viabilização de uma coalizão democratizante e, de outro, o imperativo ético de enfrentamento das violências praticadas pelos agentes estatais e o compromisso político por maior efetividade do Estado democrático de direito. As páginas finais do pósescrito trazem informações sobre os processos de "acerto de contas" na Argentina, no Uruguai e no Chile, fazendo um contraponto com as particularidades que este processo assumiu no Brasil. Uma 
comparação mais aprofundada entre esses países foi empreendida em sua pesquisa de doutorado, defendida em março de $2008 .{ }^{1}$ Novas informações e análises possibilitam um entendimento mais apurado do processo brasileiro: as violações são equiparadas a danos patrimoniais; as instituições estatais adotam medidas para que os violadores jamais sejam nomeados e responsabilizados; e o discurso de setores militares, calcado na idéia de que se lutava contra a ameaça do comunismo e de que se tratava de um estado dede guerra, busca justificar o inaceitável.

Ao longo de todos esses anos nossas lideranças políticas não enfrentaram essa questão, tendo, por vezes, desqualificado sua relevância em comparação com outros problemas sociais, como a desigualdade, ou tergiversaram diante de ameaças e vetos, adotando medidas paliativas. Protelou-se tal enfrentamento com a expectativa de que o tempo seria capaz de selar nossas divisões políticas. A Lei de Anistia de 1979 não só corroborou nesse sentido, mas também serviu de apoio para a permanência dos quadros do regime autoritário nas instituições estatais. A auto-anistia serviu para validar prisões ilegais, tortura e execuções sumárias, atos praticados por agentes do aparato da segurança pública e apoiados, ou tolerados, por agentes das instituições judiciais. Os governos estaduais eleitos a partir de 1982 não foram capazes de provocar mudanças no setor público, cuja continuidade institucional serviu de apoio para a mobilização agressiva da opinião pública contra os "direitos humanos", com o objetivo de bloquear iniciativas de controle e de reforma do aparato de segurança pública. As conseqüências de tal tibieza são ainda hoje amplas e difusas, projetando-se em temas centrais para a sociedade brasileira, como a violência institucional, a segurança pública e a corrupção.

Contudo, isso não quer dizer que houve arrefecimento da ação de grupos comprometidos com os direitos humanos e o Estado de direito. Pelo contrário, as pressões nesse sentido são recorrentes na agenda política, embora as respostas do Estado sejam parciais e enviesadas. O acerto de contas é, então, um processo político inconcluso, cujos atores ainda procuram redefinir o sentido político e os limites da Lei de Anistia de 1979. Essa discussão permanece, portanto, no centro da agenda e da institucionalidade política da fundação de "nosso" Estado democrático de direito.

O livro de Glenda Mezarobba surge como referência para o debate acerca da transição e da consolidação da democracia no Brasil, e pode ser lido como um memorial das tentativas de resolver de forma adequada a questão que nos desafia e, assim, superar o legado de arbítrio do Estado brasileiro durante o regime autoritário. O livro também é uma contribuição de relevo para a análise crítica das relações entre democracia, Estado de direito e direitos humanos.

A questão da violação não calou e nem vai calar na política brasileira porque nela estão colocadas as próprias condições para a instituição social de um Estado democrático de direito efetivo e de alcance universal; porque envolve os aspectos mais fundamentais de uma sociedade que se conforma aos princípios e às regras de direito, não se baseando apenas na coexistência de indivíduos que vivem num mesmo território, mas na sua conformação como coletividade, portadores de uma história comum.

A ordem do direito não é apenas a das regras impostas por um soberano, mas também diz respeito àquilo que torna possível a passagem da guerra aberta à política, permitindo a conformação de um espaço para a expressão pública dos antagonismos e sua resolução. A ordem do direito permite que narrativas disjuntas sobre as lutas sociais encontrem um termo, configurando-se uma coletividade que partilha uma história e constrói sua memória comum. Nesse sentido, a transição democrática ainda não instituiu a sociedade brasileira enquanto ordem de direito, já que uma parcela significativa da população - tanto os que se insurgiram contra a dominação ilegal e ilegítima do regime autoritário, como aqueles que foram involuntariamente atingidos - é privada de seus direitos mais fundamentais, ligados à vida, à dignidade e à segurança. Eles precisam saber o destino de seus próximos, dados como desaparecidos, receber os corpos dos mortos e fazer os rituais funerários, conhecer em que circunstâncias essas pessoas foram submetidas àquelas violações, saber quem as praticou, ordenou ou admitiu e, principalmente, estarem certas de que tais atos serão julgados de acordo com as regras e os 
princípios do Estado de direito, para que se possam determinar as responsabilidades e as punições.

Não se tem uma ordem de direito fundada entre nós também porque se mostra a incapacidade dos governantes eleitos de controlarem todo o aparato estatal, dirigindo o conjunto de suas agências no sentido da realização dos direitos e das garantias fundamentais dos cidadãos e o cumprimento de compromissos assumidos com a adesão às declarações e aos pactos internacionais de direitos humanos. $\mathrm{O}$ veto de setores militares e seus aliados civis a propostas de adoção de políticas estatais para a reconstrução da verdade, da responsabilidade e da reparação, aliado ao imobilismo da maioria das lideranças políticas do país diante desse contexto, significam que o Estado democrático de direito organizado pela Constituição de 1988 ainda não foi instituído socialmente no Brasil.

Pretende-se justificar as violações de direitos humanos com uma retórica baseada na idéia de segurança nacional, revigorando a divisão entre setores da sociedade que se envolveram na luta e proclamando a vitória de um setor sobre o outro. Ao tentar justificar o injustificável (como se a situação de guerra permitisse ao Estado brasileiro violar as regras e os princípios do direito constitucional e dos tratados de direito internacional dos direitos humanos, do direito humanitário e do direito da guerra), selecionando informações sobre os conflitos políticos da época, essa visão coloca em questão a própria transição democrática e o caráter inaugural da Constituição de 1988.

Somos todos atingidos e estamos, portanto, implicados na questão das reparações às violações de direitos humanos praticadas durante o regime autoritário. Fazemos parte de uma sociedade fraturada no que concerne à sua própria fundação como ordem constitucional democrática. Compartilhamos o sofrimento e as apreensões daqueles que não receberam resposta aceitável para atos de morte, tortura ou desaparecimento forçado, e não sabemos a extensão do compromisso e da capacidade de os governos efetivarem e horarem a carta constitucional.

Os governantes brasileiros deixaram de enfrentar as violações de um modo compatível com os princípios e as regras dos direitos humanos e do Estado de direito, sobretudo quando se trata da me- mória dos mortos e desaparecidos e da dignidade de seus familiares e próximos. Eles adotam um duplo padrão de ação: de um lado, afirmam o respeito aos direitos e às garantias individuais, mas, de outro, em nome da segurança do Estado, procuram preservar a todo custo informações sobre assuntos internos, não cumprindo seu dever de transparência, manutenção de registros e promoção da responsabilidade individual, seja criminal, seja administrativa ou disciplinar. Cabe lembrar a timidez e a limitação das instituições judiciárias brasileiras, como se suas garantias funcionais e profissionalismo, comparativamente maiores que os de seus colegas em países vizinhos, produzissem um distanciamento das questões políticas fundamentais, porém polêmicas.

Um acerto de contas com o futuro mostra, então, as implicações do veto político ao enfrentamento das violações de direitos humanos pelos agentes do Estado durante o regime autoritário para a instituição social de um Estado de direito, a promoção de reformas que o tornem efetivo e universal e a construção de uma sociedade plenamente democrática no Brasil.

\section{Nota}

1 Glenda Mezarobba. O preço do esquecimento: as reparações pagas às vitimas do regime militar (uma comparação entre Brasil, Argentina e Chile). Tese de doutorado em Ciência Política, FFLCH/USP, 2008.

\section{ANDREI KOERNER \\ é professor do Departamento de Ciência Política do IFCH/Unicamp. E-mail: andreik@uol.com.br.}

\author{
SAN ROMANELLI ASSUMPÇÃO \\ é doutoranda no Programa de Pós-Graduação \\ de Ciência Política da FFLCH-USP. \\ E-mail: srassumpcao@yahoo.com.br.
}

